\title{
A Single-Phase Photovoltaic Grid-Connected Power Control with ADRC Optimization
}

\author{
Yuan Zheng, Hejin Xiong and Deming Lei \\ School of Wuhan University of Technology, China \\ School of Wuhan University of Technology, China \\ School of Wuhan University of Technology, China \\ email: 493678673@qq.com \\ email: 2862696416@qq.com \\ email: 1275967473@qq.com
}

\begin{abstract}
Key Words: PVPC; LCL filtering; ADRC; power control
Abstract. Photovoltaic Power Control (PVPC) system is an integrated system that consists of photovoltaic grid-connected system and LCL filtering system. It is susceptible to power grid disturbance and external environment changes. Based on these characteristics of this system, this paper uses the auto-disturbance rejection control technology-ADRC, which has strong anti-jamming ability inside and outside. The simulation result shows that the ADRC controller can achieve the desired control effect. It is showed that the ADRC controller can obtain better control effects compared with the PI control. The application of ADRC control has a nice prospect in PVPC system.
\end{abstract}

\section{Introduction}

After 21st century, how to develop economy under the restriction of limited energy and environmental protection has become a hot issue among most of countries ${ }^{[1-2]}$. Solar energy is the most promising renewable energy, photovoltaic power generation is the most important form of energy supply. In [3], the inverter is directly connected to the grid by full-bridge circuit, but this control system's structure is simple and has many devices, which leads to it costs a lot of money. The grid-connected inverter was designed in [4-5], but the circuit adopts the AC-DC-AC structure which increases the complexity of the system. In[6], it studied the strategy of PV grid-connected control which has reactive power compensation and it has been applied in the synchronous rotating coordinate system, it can adjust the active and reactive power separately in the synchronous rotating coordinate system to realize the static difference, however, the detection of reactive load current is the key to realize active power generation and reactive power compensation, actually, it's hard to detect the reactive load current . The three-phase system or the two-phase orthogonal system is used to obtain the virtual current in different coordinate systems. There is no doubt that it will bring different degrees of delay, and the stability of the system will be influenced. Therefore, a current tracking control strategy based on ADRC is proposed in this paper, this control strategy can restrain various disturbances effectively and have reliable performances, strong robustness, fast response and it do not rely on the mathematical model of controlled objects.

\section{The Design of Main Circuit}

The structure of single-phase PVPC control system with ADRC optimization is shown in Fig. 1.The design of the former level is DC / DC boost circuit by controlling and changing the duty ratio of the IGBT to change the output voltage of the PV array, while achieving maximum power tracking. The latter level is the structure of the single-phase inverter that makes the PV model's output current changes from DC to AC. The inverter is controlled by the PWM trigger. This system has nice flexibility and the former and the latter can run independently. 
The output voltage is higher than the input voltage in the DC / DC boost circuit, the maximum power point voltage of the PV array can be lower than the DC bus voltage. It can increase the power generation effectively, in addition, the diode in boost circuit can prevent the AC side of the grid back to the DC side, so it improve the reliability of system's operation.

The open-loop transfer function $G_{0 \text {-open }}(s)$ of inverter output signal $\mathrm{i}_{0}$ to the LCL current $\mathrm{i}_{g}$ is:

$$
G_{0-\text { open }}(s)=\frac{K_{g} K_{i n v^{s}}}{s\left(s+w_{g}\right)\left(L L_{g}+L+L_{g}\right)}
$$

Introducing the single current feedback, ignoring the parasitic resistance of the filter, the function $G_{0}(s)$ of closed-loop transfer is calculated in following formula:

$$
G_{0}(s)=\frac{K_{i n v}\left(\mathrm{~s}+w_{g}\right)}{s\left[L L_{g} C s^{3}+L L_{g} C w_{g} s^{2}+\left(L+L_{g}\right) s+\left(L+L_{g}\right) w_{g}-K_{\mathrm{g}} K_{i n v}\right]}
$$

LCL filter parameters: $\mathrm{R}=0.001 \Omega, \mathrm{L}=0.03 \mathrm{H}, \mathrm{C}=1 * 10-6 \mathrm{~F}$.

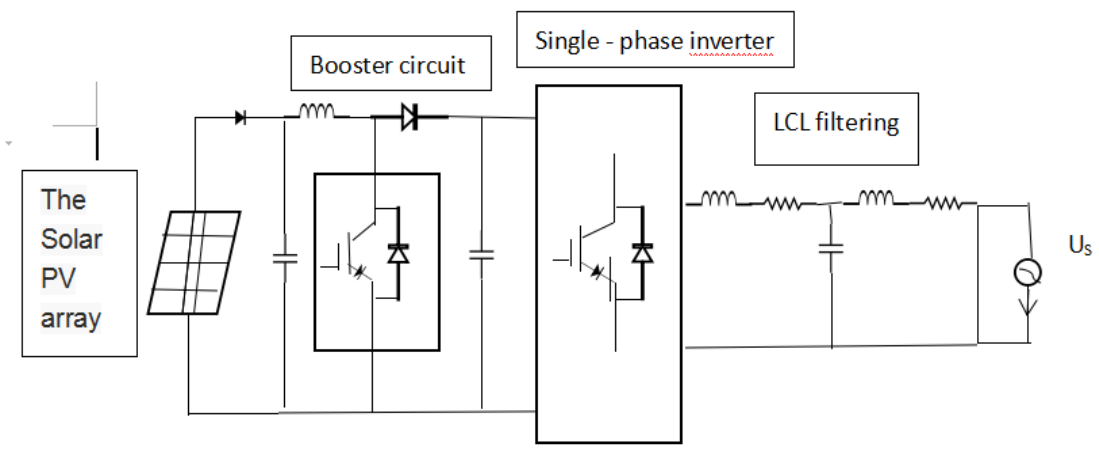

Fig. 1: the structure of single-phase PVPC control system

At present, the main control methods are: hysteresis current control, dual closed-loop control, space vector control, deadbeat control and repetitive control ${ }^{[7]}$. The voltage and current loop control was adopted to realize the stabilization of the whole system in double closed-loop. The current tracking control network is shown in Fig. 2.The method of obtaining the reference voltage $U_{\max }$ is to collect the photovoltaic current and voltage and use the MPPT control. The first step is comparing $U_{\max }$ and the actual voltage of the photovoltaic voltage $U_{d}$, adjusting the error by PI controller then get reference current $I_{\text {ref }}$, then using $I_{\text {ref }}$ multiplied with sine to get given current $i_{g}\left(i_{g}\right.$ is ADRC reference current), and next comparing $i_{g}$ with the output current $i_{f}$ to get the current deviation signal $e_{i}$, finally, $e_{i}$ can be adjusted by ADRC controller to obtain a satisfactory current ${ }^{[8]}$.

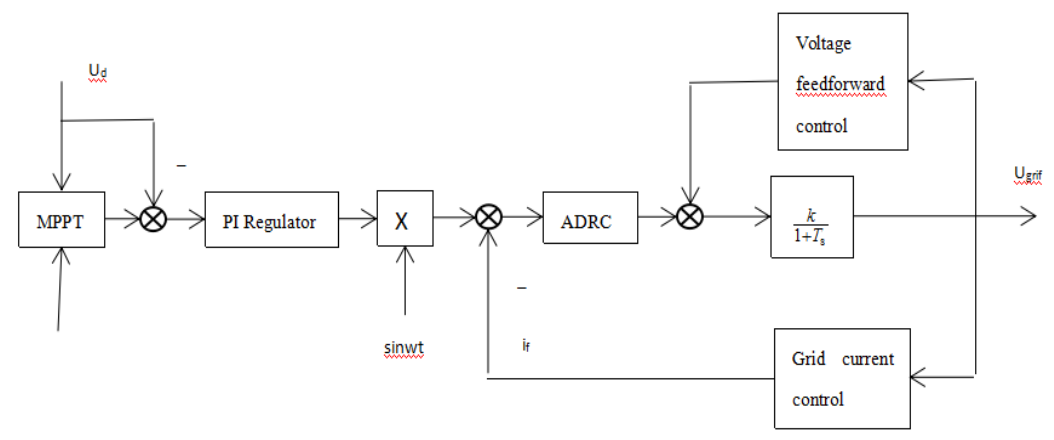

Fig. 2: Current tracking and control principle based on ADRC

The transfer function of the output current is shown in the following formula: 


$$
\begin{aligned}
& I=\frac{G_{P I}(S) G_{i n v}(S)}{S L+S / C+R+G_{P I}(S) G_{i n v}(S)} I^{*}-\frac{G_{P I}() G_{i n v}()}{S L+S / C+R+G_{P I}()+G_{i n v}()}\left(U_{\text {grid }}+\mu\right) \\
& G_{P I}(S)=\frac{K_{P} S+K_{I}}{S} \\
& G_{\text {inv }}(S)=\frac{K P W M}{K_{P W M} S+1}
\end{aligned}
$$

It can be seen from the formula that the current of inverter outputs and the current of reference are related to grid voltage, the use of ADRC closed-loop control can suppress the disturbance of power grid.

\section{ADRC Design and Parameter Tuning}

In this section, I will explain the design of ADRC and it's principles. A three order auto disturbance rejection controller structure is given in Fig. 3.

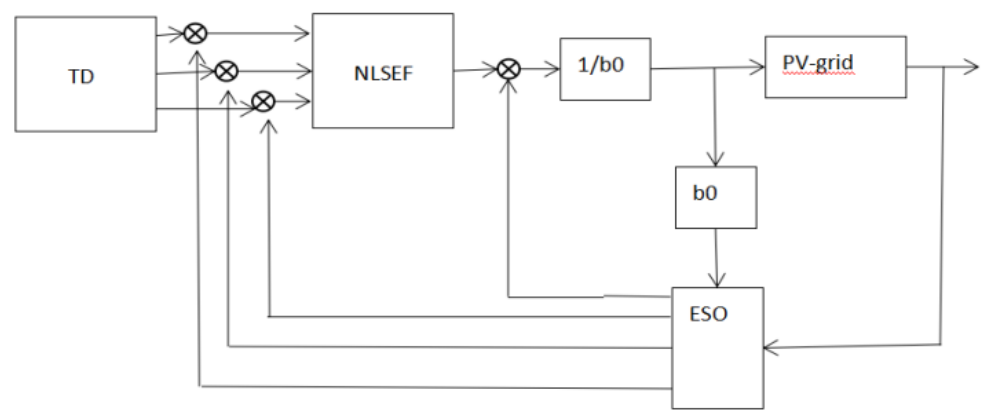

Fig. 3 A three order auto disturbance rejection controller structure

\section{Abbreviations and Acronyms Transition process (TD)}

In the general control system, the error is directly taken as the setting value $e=v-y, v$ is the setting value and $y$ is the output. The error of this method makes the initial error is very large, easily lead to overshoot. According to the bearing capacity of the object, we arrange a reasonable transition process:

$$
\left\{\begin{array}{l}
\dot{v_{1}}=v_{2} \\
\dot{v_{2}}=v_{3} \\
\dot{v_{3}}=u\left(v_{1}-v_{0}, v_{2}, v_{3}\right) \\
u\left(v_{1}-v_{0}, v_{2}, x_{3}\right)=-r \operatorname{sign}\left(v_{1}-v_{0}+s\left(s v_{2}+\frac{v_{3}^{2}}{2 r}\right)\left(\frac{1}{\sqrt{r}} \sqrt{s v_{2}+\frac{v_{3}^{2}}{2 r}}+s \frac{v_{3}}{r}\right)-\frac{v_{3}^{3}}{6 r^{2}}\right) \\
s=\operatorname{sign}\left(v_{2}+\frac{\left|v_{3}\right| v_{3}}{2 r}\right)
\end{array}\right.
$$

Among all of these, ${ }^{v_{1}}$ is the arrangement of the transition signal, ${ }^{v_{2}}$ is the arrangement of the transition process of differential signal, ${ }^{v_{3}}$ is the arrangement of the transition process of the two order differential signals. Such arrangement is a very good solution to the contradiction between the rapid response of the system and the overshoot. 


\section{Extended state observer (ESO)}

Table. 1 calculated data in different controller

\begin{tabular}{|c|c|c|c|}
\hline Controller & Rise Time(s) & Overshoot & Setting Time(s) \\
\hline PID Controller & 0.7 & $17 \%$ & 6 \\
\hline ADRC Controller & 1.2 & $1 \%$ & 1.5 \\
\hline
\end{tabular}

$$
\left\{\begin{array}{l}
e=z_{1}-y \\
\dot{z_{1}}=z_{2}+\left(z_{2}-\beta_{1} e\right) \\
\dot{z_{2}}=z_{3}-\beta_{2} f a l(e, o .5, d) \\
\dot{z_{3}}=z_{4}-\beta_{3} f a l(e, 0.25, d)+b_{0} u \\
\dot{z_{4}}=-\beta_{4} f a l(e, 0.125, d) \\
\operatorname{fal}(e, a, d)= \begin{cases}e d^{(a-1)} & |e|<d \\
|e|^{a \cdot \operatorname{sign}(e)} & |e| \geq d\end{cases}
\end{array}\right.
$$

Extended state observer is the core part of self disturbance rejection controller (ADRC),its role is estimation of the object in the order state variable and object disturbance value of the real-time(non modeling dynamics and disturbance) and compensated, the linear system of integrator series structure simplifies the control of the image, in order to improve the control performance.

\section{Nonlinear state error feedback (NLSEF)}

$$
\left\{\begin{array}{l}
\varepsilon_{1}=v_{1}-z_{1} \\
\varepsilon_{2}=v_{2}-z_{2} \\
\varepsilon_{3}=v_{3}-z_{3} \\
u_{0}=\beta_{1} \operatorname{fal}\left(\varepsilon_{1}, a_{1}, d\right)+\beta_{2} \operatorname{fal}\left(\varepsilon_{2}, a_{2}, d\right)+\beta_{3} \operatorname{fal}\left(\varepsilon_{3}, a_{3}, d\right) \\
u=u_{0}-\frac{z_{4}}{b_{0}}
\end{array}\right.
$$

Nonlinear state error feedback is a nonlinear control strategy for the error between the transition process and the object state variables. $u_{0}$ is a nonlinear combination of the signal. $z_{4} / b_{0}$ is the compensation for the disturbance. $u$ is the control signal output.

\section{Simulation}

The simulation model of the control system is established on the Simulink platform based on MATLAB in this research and the simulation results are shown below.Under the standard conditions, the output (current,voltage and power) of pv array's waveform are shown in Fig. 4. The output waveform of the grid current and voltage that work under the standard conditions are shown in Fig. 5.

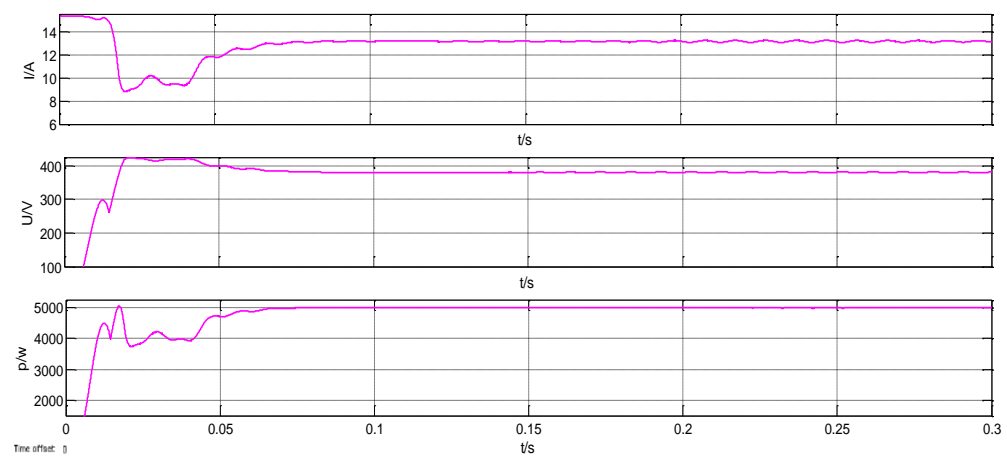

Fig. 4 the output waveform of pv array's IUP 


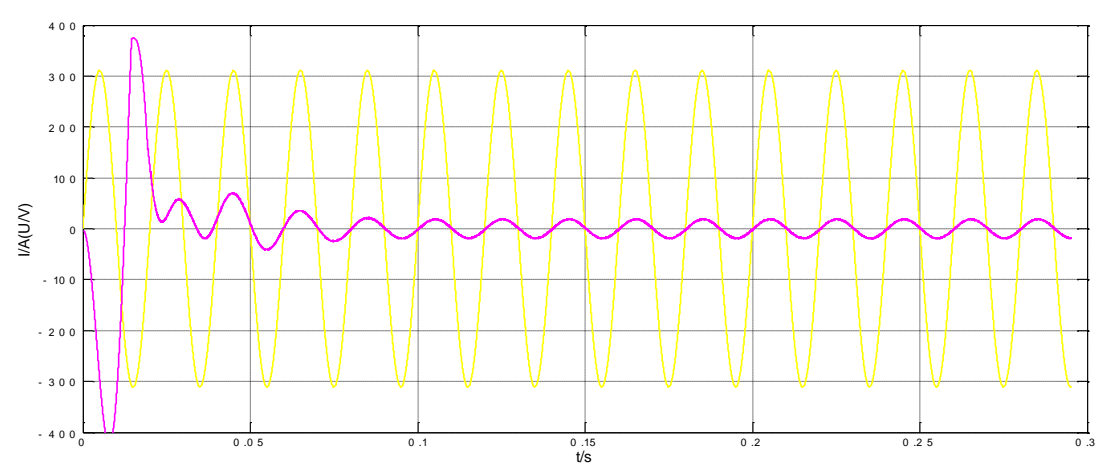

Fig. 5 the current and voltage output waveform of the grid

The standard condition is when the temperature is $25^{\circ} \mathrm{C}$ and the light intensity is $1000 \mathrm{w} / \mathrm{m}^{2}$. It can be seen that under the standard condition, the output current and voltage of the PV array are close to the voltage and current value of the maximum power point and the power is $5000 \mathrm{~W}$ which realizes the purpose of maximum power tracking. DC side voltage stabilized at $380 \mathrm{~V}$ or so and the filtering effect is obvious. It shows that the control of the inner ring phase lock of the voltage and the outer current loop has a good control effect.

When changes the light intensity from $1000 \mathrm{w} / \mathrm{m}^{2}$ to $800 \mathrm{w} / \mathrm{m}^{2}$ at $0.15 \mathrm{~s}$, the current output of pv array sharp decreases but the output of grid doesn't change. This situation is displayed in Fig. 6 and Fig. 7.It has proved this system has a good control effect again.
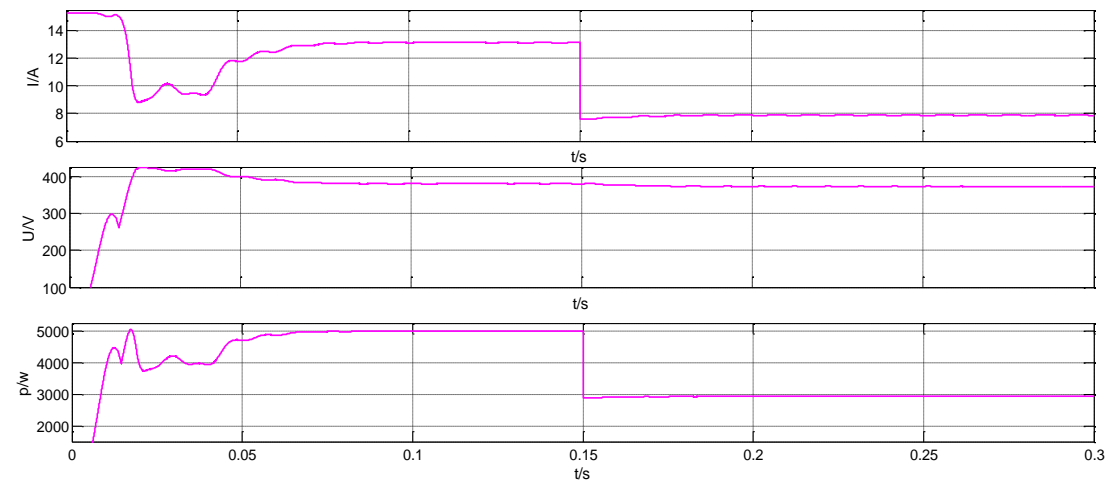

Fig. 6 the output waveform of pv array's IUP when light intensity changes

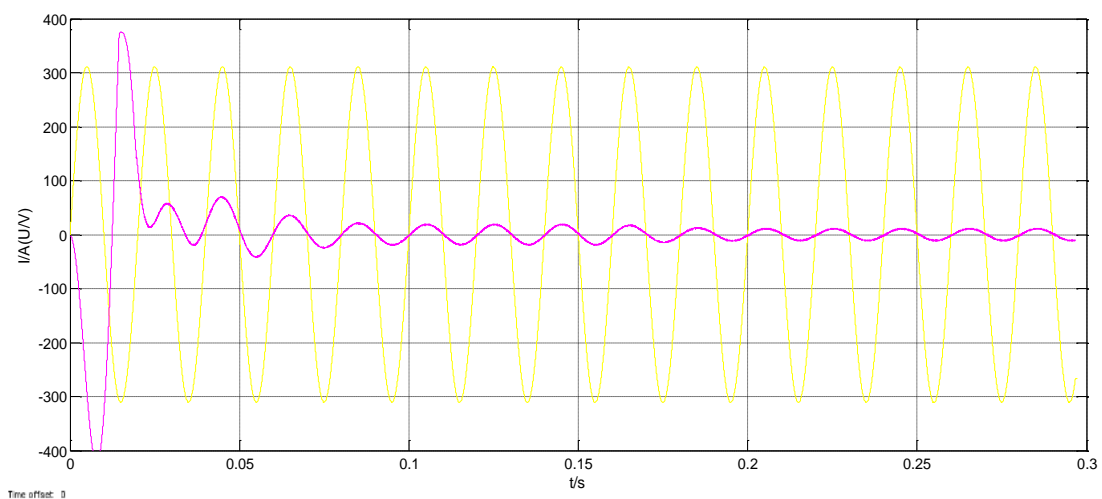

Fig. 7 the current and voltage output waveform of the grid when light intensity changes

\section{Conclusion}

The loads' current and power supply voltage are regarded as unknown disturbances of the system and they are dynamically compensated in the system of PVPC based on ADRC. It can be seen that the 
grid-connected current does not appear obvious disturbance and it can be transformed to another stable value smoothly under the control of ADRC control strategy by simulation and theoretical analysis. So, the detection of harmonic and reactive current process is simplified. At the same time, the selection of parameters can be obtained in a wide range, so the control system structure is simple and easy to carry on.

\section{Acknowledgements}

*This paper is supported by the National Natural Science Foundation of China (NO.61573264)

\section{References}

[1] Hongliang Yin and Jian Lu. Network combination electricity generation technique of solar cell [J]. China Construction: Solar \& Renewable Energy Sources, 2006, 19 (1): 57 59.

[2] Yanghua Liu and Zhengqiu Wu. A survey on distributed generation and its networking technology[J]. Power System Technology, 2008, 32 (15): 71 76.

[3] Chao Zhang and Xiangning He. A novel high-frequency DC link inverter for grid-connected photovoltaic system[J]. Automation ofElectric Power Systems, 2005, 29 (19): 51 53.

[4] Lijun Diao and Zhigang Liu. Engineering design techniques of energy-fed PWM rectifier connected to AC mains [J]. Transactions of China Electrotechnical Society, 2005, 20 (11): 75 79.

[5] Jimin Yuan, Xiaoling Li and Jianguo Wei. Soft-switching technology of grid-connected photovoltaic system [J]. Electric Power Automation Equipment, 2010, 30 (9): 85 88.

[6] Haining Wang, Jianhui Su and Guorong Zhang. Control of PV grid connected generation and reactive compensation [J]. Transactions of China Electrotechnical Society, 2005, 20 (9): 114 118.

[7] Chunshui Du and Chenghui Zhang. Control strategy on the three-phase grid-connected photovoltaic generation system with power filter [J]. Transactions of China Electrotechnical Society, 2010, 25 (9): 163 169.

[8] Yi Huang and Wenge Zhang. Development of active disturbance rejection controller [J]. Control Theory \& Applications, 2005, 19 (4): 485 492. 